\title{
Theoretical Issues in the Further Development of the Sense of Coherence Construct
}

\author{
Jacek Hochwälder
}

\section{Introduction}

Kurt Lewin (1951, p. 169), one of the founding fathers of social psychology, famously surmised, there is nothing so practical as a good theory. A tenet of philosophy (see, e.g., Chalmers, 1982) is that empirical research without some guidance from a theory or model may result in insensible observations. On the other hand, a theory or model that is not exposed to rigorous theoretical scrutiny and empirical testing risks becoming dogmatic and incorrect. Therefore, although it is highly valuable to have a theory or model that guides research, it is imperative to examine and test it empirically.

Antonovsky (1979) introduced the salutogenic model of health, in which the sense of coherence construct is a core concept. This chapter aims to discuss some issues that need to be further explored in future research on the sense of coherence construct. The chapter starts with a brief overview of the salutogenic model and the sense of coherence construct. After that, issues related to the construct will be discussed, and directions for future research suggested.

\section{A Brief Overview of the Salutogenic Model and the Sense of Coherence Construct}

Antonovsky $(1979,1987)$ introduced the salutogenic perspective as a complement to the well-established pathogenic perspective. An overview of the main characteristics of and contrasts between the two perspectives is shown in Table 53.1. In brief, the salutogenic perspective aims to explore the origins of health and focus primarily on how to promote health, while the pathogenic perspective deals with the causes of diseases and mainly focuses on how to cure and prevent ill health. For a comprehensive discussion of the dif-
Table 53.1 Some characteristics of, and contrasts between, the salutogenic and the pathogenic perspective

\begin{tabular}{|c|c|}
\hline Salutogenic perspective & Pathogenic perspective \\
\hline $\begin{array}{l}\text { Health is heterostatic: Relatively } \\
\text { changeable }\end{array}$ & $\begin{array}{l}\text { Health is homeostatic: } \\
\text { Relatively static }\end{array}$ \\
\hline $\begin{array}{l}\text { Health is subjected to entropy: } \\
\text { Spiral down towards disease and } \\
\text { death }\end{array}$ & $\begin{array}{l}\text { Health is a normal state: Ill } \\
\text { health and disease are an } \\
\text { anomaly or an abnormal state }\end{array}$ \\
\hline $\begin{array}{l}\text { Health is a continuum: The } \\
\text { health ease - Disease continuum }\end{array}$ & $\begin{array}{l}\text { Health is a dichotomy: The } \\
\text { healthy/sick dichotomy }\end{array}$ \\
\hline $\begin{array}{l}\text { Holistic: The focus is on the } \\
\text { whole history of the person }\end{array}$ & $\begin{array}{l}\text { Specific: The focus is on a } \\
\text { specific disease or diagnosis of } \\
\text { the person }\end{array}$ \\
\hline $\begin{array}{l}\text { Salutary factors: The focus is on } \\
\text { factors that create health }\end{array}$ & $\begin{array}{l}\text { Risk factors: The focus is on } \\
\text { factors that create disease }\end{array}$ \\
\hline $\begin{array}{l}\text { Stressors and tension might be } \\
\text { pathogenic, neutral or } \\
\text { salutogenic }\end{array}$ & $\begin{array}{l}\text { Stress and tension are } \\
\text { pathogenic }\end{array}$ \\
\hline $\begin{array}{l}\text { Active adaption: In a therapeutic } \\
\text { or treatment situation, the } \\
\text { important factors are the person's } \\
\text { ability to adapt and make use of } \\
\text { the available resources actively }\end{array}$ & $\begin{array}{l}\text { The 'magic bullet': In a } \\
\text { therapeutic or treatment } \\
\text { situation, the important factors } \\
\text { are to give the person the 'right' } \\
\text { diagnosis and find the 'right' } \\
\text { treatment }\end{array}$ \\
\hline $\begin{array}{l}\text { The 'deviant' case: Look for the } \\
\text { deviant case(s). For example, } \\
\text { attending and noting in the data } \\
\text { that some of the people that have } \\
\text { been through horrible conditions } \\
\text { (e.g. concentration camp) stay } \\
\text { well and healthy (and asking } \\
\text { what makes them stay well and } \\
\text { healthy) }\end{array}$ & $\begin{array}{l}\text { Hypothesis confirmation: Try to } \\
\text { confirm hypotheses. For } \\
\text { example, just searching and } \\
\text { looking in the data if most of } \\
\text { the people that have been } \\
\text { through horrible conditions do } \\
\text { not feel well and do get sick (in } \\
\text { order to get the assumed } \\
\text { relation confirmed) }\end{array}$ \\
\hline $\begin{array}{l}\text { Health-oriented } \\
\text { Enhance and strengthen health } \\
\text { Approach potentials for health } \\
\text { Create/maximize salutary } \\
\text { factors } \\
\text { Oriented to all people }\end{array}$ & $\begin{array}{l}\text { Disease-oriented } \\
\text { Cure and treat diseases } \\
\text { Avoid causes of diseases } \\
\text { Eliminate/minimize risk } \\
\text { factors } \\
\text { Oriented only to those having } \\
\text { disease }\end{array}$ \\
\hline $\begin{array}{l}\text { Proactive: Create conditions for } \\
\text { health and Well-being }\end{array}$ & $\begin{array}{l}\text { Reactive: React to indications } \\
\text { of disease }\end{array}$ \\
\hline
\end{tabular}

J. Hochwälder $(\bowtie)$

Department of Psychology, Mälardalen University,

Eskilstuna, Sweden

e-mail: jacek.hochwalder@mdh.se

ferences between the two perspectives see, for example, Becker et al. (2010) and Vinje et al. (2017). 
Antonovsky (1979, 1987) described his salutogenic model of health in the form of a flowchart, and by formulating numerous postulates, which are scattered throughout his writings. The flowchart is presented in Fig. 53.1, and some of the postulates, which are of relevance for this study, will be described later on in this chapter.
Throughout the years, the theoretical relations described in the flowchart and the various postulates in his texts have inspired and guided many theoretical discussions and much empirical research. In this chapter, the focus will be on some issues related to a limited number of concepts and relations in the salutogenic model. Before discussing these issues, it is

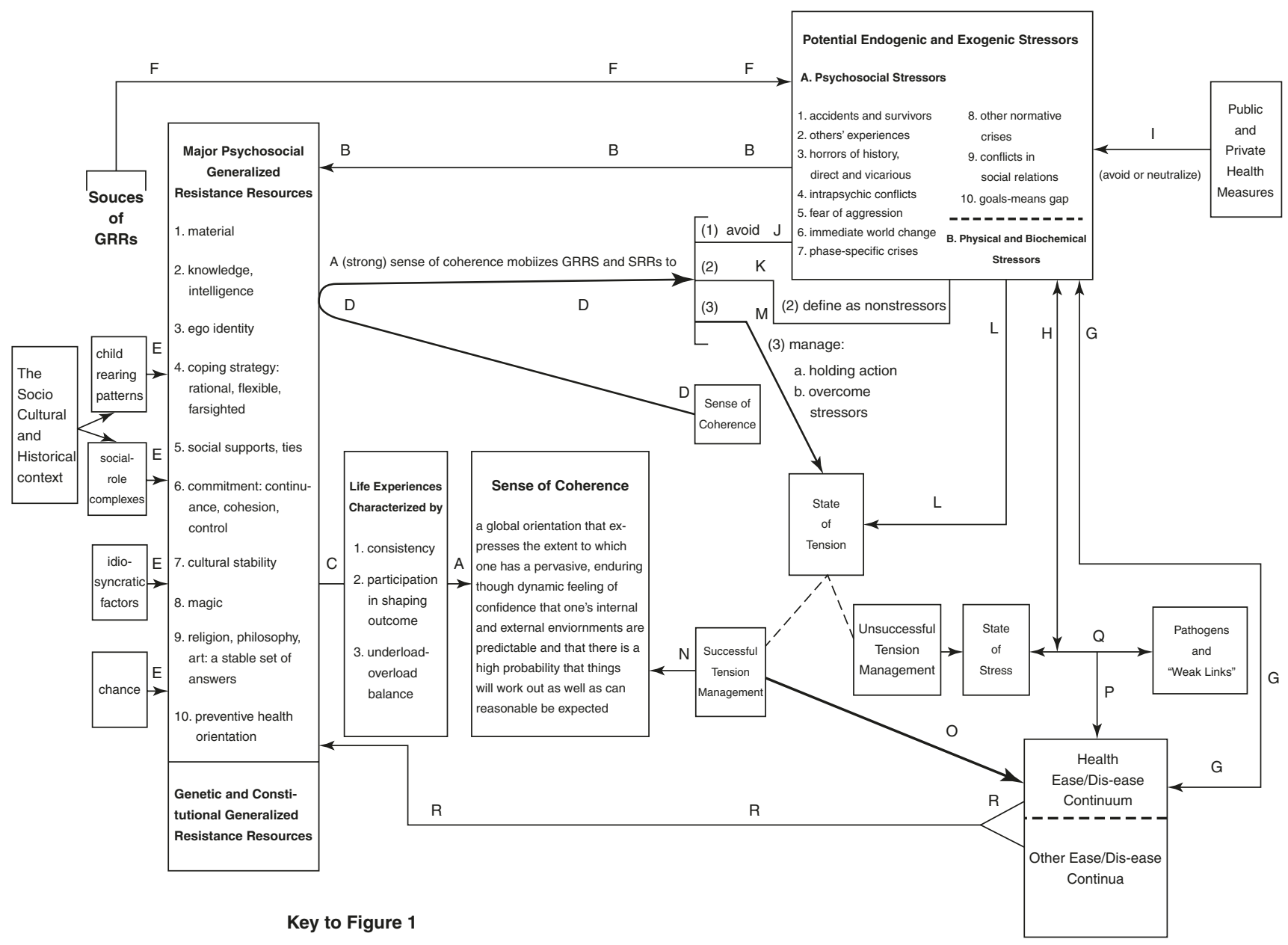

Arrow A: Life experiences shape the sense of coherence.

Arrow B: Stressors affect the generalized resistance resources at one's disposal. Line C: By definition, a GRR provides one with sets of meaningful, coherent life experiences.

Arrow D: A strong sense of coherence mobllizes the GRRs and SRRs at one's disposal.

Arrows E: Childrearing patterns,social role complexes, idiosyncratic factors, and chance build up GRRs.

Arrow F: The sources of GRRs also create stressors.

Arrow G: Traumatic physical and biochemical stressors affect health status directly; health status affects extent of exposure to psychosocial stressors.

Arrow $\mathrm{H}$ : Physical and biochemical stressors interact with endogenic pathogens and "weak links" and with stress to affect health status.

Arrow I: Public and private health measures avoid or neutralize stressors.

Line J: A strong sense of coherence, mobilizing GRRS and SRRs, avoids stressors.
Line K: A strong sense of coherence,mobilizing GRRS and SRRs, defines stimuli as nonstressors.

Arrow L: Ubiquitous stressors create a state of tension.

Arrow M: The mobilized GRRs (and SRRs) interact with the state of tension and manage a holding action and the overcoming of stressors.

Arrow N: Successful tension management strengthens the sense of coherence.

Arrow O: Successful tension management maintains one's place on the health ease/dis-ease continuum.

Arrow P: Interaction between the state of stress and pathogens and "weak links" negatively affects health status.

Arrow Q: Stress is a general precursor that interacts with lhe existing potential endogenic and exogenic pathogens and "weak links."

Arrow R: Good health status facilitates the acquisition of other GRRs.

Note: The statements in bold type represent the core of the salutogenic model.

Fig. 53.1 The salutogenic model of health, from Antonovsky (1979, pp. 184-185) 
necessary to give a brief overview of the relevant parts of the model.

The salutogenic model rests on two main postulates: (a) that we humans are always under the attack of various stimuli, which often leads to heterostasis or a state of imbalance and (b) that unless we can cope with these stimuli, they will result in entropy or a movement towards disorder and disease (Antonovsky, 1979, 1987). According to Antonovsky, a stimulus can be evaluated as neutral (irrelevant), positive (beneficial) or harmful. Furthermore, he stated that a stimulus can be defined as a stressor if it elevates entropy and that stressors can be classified into chronical stressors (e.g. a disability), main life events (e.g. death of a loved family member) and daily hassles (e.g. an argument with one's boss at work).

The generalized resistance resources (GRRs) play a central role in the model and a GRR is defined as a "physical, biochemical, artefactual-material, cognitive, emotional, valuative-attitudinal, interpersonal-relational, macro sociocultural characteristic of an individual, primary group, subculture, society that is effective in avoiding, combating a wide variety of stressors and thus preventing tension from being transformed into stress' (Antonovsky, 1979, p. 103). Antonovsky assumed that what GRRs have in common is that they relate to a sense of consistency, possibility to affect underload-overload and to be able to shape outcomes in life experiences (see Fig. 53.1, arrow C). Furthermore, he suggested that the repeated use of available GRRs in various life experiences will result in a relatively stable dispositional orientation, which he called the sense of coherence (SOC) (see Fig. 53.1, arrow A).

The SOC is the central concept in the model and is defined as 'a global orientation that expresses the extent to which one has a pervasive, enduring though dynamic feeling of confidence that: (1) the stimuli deriving from one's internal and external environments in the course of living are structured, predictable, and explicable; (2) the resources are available to one to meet the demands posed by these stimuli; and (3) these demands are challenges, worthy of investment and engagement' (Antonovsky, 1987, p. 19). From this definition, it follows that SOC comprises three components: (1) a cognitive component, labelled comprehensibility, representing the extent of the belief that the problem faced is apparent; (2) a behavioural component, labelled manageability, representing the extent of the belief that one will be able to cope with the problem successfully and (3) a motivational component, labelled meaningfulness, representing the extent of the belief that one wishes to cope with the problem. A strong SOC indicates that life is being perceived as highly comprehensible, manageable and meaningful. According to the model, a person with a strong SOC should be able to avoid stressors better than one with a weak SOC, appraise stressors as less stressful than a person with a weak SOC and be able to cope more successfully with a stressor (see Fig. 53.1, arrows $\mathrm{J}, \mathrm{K}$ and $\mathrm{M}$ ).

SOC is usually measured with a self-rating scale - The Orientation to Life Questionnaire (hereafter referred to as the SOC scale) - developed by Antonovsky (1987, 1993). The scale was constructed using facet design (Guttman, 1974; Shye, 1978). Five aspects or facets were varied between the questions. More specifically, the respondents were asked to rate (a) the degree of experienced comprehensibility, manageability or meaningfulness (SOC facet); (b) when confronted with an instrumental, a cognitive or an affective stimuli (modality facet); (c) which derives from the persons internal world, external world or both worlds (source facet); (d) which constitutes a real, an ambiguous or an abstract demand (demand facet) and (e) takes place in the past, the present or the future (time facet). The full version of the scale consists of 29 questions (where 11, 10 and 8 of the 29 questions measure comprehension, manageability and meaningfulness respectively) and the short version consists of 13 questions (where 5, 4 and 4 of the 13 questions measure comprehension, manageability and meaningfulness respectively). Responses to each question are given using a sevenpoint scale, ranging from 1 to 7 . Responses to 13 of the 29 questions in the full version and 5 of the 13 questions in the short version must be reversed before a subtotal index is computed. A higher numeric value represents a stronger SOC. The psychometric properties of the SOC scale have been systematically reviewed in two studies (see Antonovsky, 1993; Eriksson and Lindström, 2005), and from these reviews, it can be concluded that the SOC scale is (a) reliable and (b) valid, but that (c) the factorial structure of the scale is not clear and (d) the scores on the scale over time are moderately stable. Also, systematic reviews have shown that SOC is positively related to mental health (Eriksson and Lindström, 2006) and quality of life (Eriksson and Lindström, 2007), weakly related to physical health (Eriksson and Lindström, 2007; Flensborg-Madsen et al., 2005) and negatively related to mortality (Surtees et al., 2003, 2006a, 2006b).

\section{Some Issues for Future Research on the Sense of Coherence Construct}

Since SOC was introduced, various criticisms have been levelled against the construct (see, e.g. Eriksson, 2015a; Geyer, 1997; Griffiths, 2010; Kumlin, 1998a, 1998b). The aim of this chapter is not to review and discuss all the criticisms, but to briefly indicate some essential issues that have not received enough attention and to give some directions for future research on SOC.

The issues that will be discussed in this chapter are as follows: (1) the dimensionality of the SOC scale; (2) SOC as the causal variable; (3) SOC as the outcome variable; (4) 
Table 53.2 The dynamic connection between the three SOC components (Antonovsky, 1987, p. 20)

\begin{tabular}{l|l|l|l|l}
\hline & Component & & \\
\hline Type & Comprehension & Manageability & Meaningfulness & Predicted change \\
\hline 1 & High & High & High & Stable \\
\hline 2 & Low & High & High & Unusual \\
\hline 3 & High & Low & High & Press upward \\
\hline 4 & Low & Low & High & Press upward \\
\hline 5 & High & High & Low & Press downward \\
\hline 6 & High & Low & Low & Press downward \\
\hline 8 & Low & Low & Low & Unusual \\
\hline
\end{tabular}

general SOC and domain-specific SOC; (5) the concept of boundary in the measurement of SOC; (6) the dichotomization and trichotomization of SOC; (7) the importance of relating SOC to salutogenic outcome measures; (8) various kinds of additional issues: (a) studying the collective SOC, (b) measuring other central constructs in the salutogenic model and (c) the importance of literature reviews and meta-studies.

\section{The Dimensionality of the SOC Scale}

Antonovsky $(1987,1993)$ was very clear that only one single total score should be calculated based on answers to all the questions of the scale and not three separate scores for each of the three components of comprehensibility, manageability and meaningfulness. The somewhat unclear, theoretical argument for this is that Antonovsky (1987) assumed that every single GRR contributes to all three components, which, according to him, implies that the three components are insolubly interlaced with each other. The methodological argument is that using facet theory in the development of the scale makes it impossible to separate the three components because, besides the SOC facet, there are, as previously mentioned, four additional facets that affect the factorial structure of the scale (see Antonovsky, 1987). As referred to previously, psychometric evaluations of the SOC scale have not given univocal results concerning the scale's dimensionality (see Antonovsky, 1993; Eriksson and Lindström, 2005).

The problem - which Antonovsky was very much aware of - is that although the SOC concept is defined as consisting of three distinct components, the three components cannot be measured separately by the SOC scale. In the article where he first thoroughly described the scale and its psychometric properties, he concluded that 'It would indeed be a contribution were separate measures of the components to be developed, with relatively low interrelations' (Antonovsky, 1993, p. 732). Also, in his last article, where he discussed SOC from a historical and a future perspective, he suggested that one of the tasks for future research is to construct a scale where the three components can be measured separately
(Antonovsky, 1996a). However, such a scale has not yet been developed.

There are numerous fundamental assumptions/postulates and interesting questions/problems in Antonovsky's writings that could be tested if the three dimensions could be measured relatively independently of each other. Here are four examples. Firstly, two fundamental questions that could be answered are: (a) how strongly are the three components related to each other and (b) the relative importance of the three components, when related to various criterion measures (e.g. health, ill health, happiness and various types of performance). Secondly, as mentioned earlier, Antonovsky (1987) assumed that every single GRR contributes to all three components. This assumption cannot be fully and correctly explored using the SOC scale because it does not measure the three independently. Thirdly, a central and fundamental assumption in Antonovsky's salutogenic model is that life experiences (e.g. in the family, at school, at work) characterized by (1) consistency or predictability should enhance comprehensiveness, (2) underload-overload balance should enhance manageability and (3) participation in shaping outcomes should enhance meaningfulness (Antonovsky, 1979, 1987). Also, this fundamental postulate in the salutogenic model cannot be tested using the SOC scale because the three components are not independently measured. Fourthly, Antonovsky (1987) hypothesized that meaningfulness was the most important dimension, followed by comprehension that in turn was followed by manageability. $\mathrm{He}$ reasoned that if the three dimensions could be measured separately and the scores on each dimension dichotomized, then respondents could be divided into eight types, as shown in Table 53.2 (Antonovsky, 1987, p. 43). He then hypothesized that: types 1 and 8 have a stable SOC; types 2 and 7 are unusual because high manageability presupposes high comprehension; types 3 and 6 are pressed for change, but if the change will result in lower or higher SOC is dependent on the level of meaningfulness, where the high meaningfulness of type 3 should in the long run lead to high manageability and, consequently, a higher SOC. The low meaningfulness of type 6 should, in the long run, lead to a low comprehension and, consequently, a lower SOC. Types 4 and 5 also illustrate 
the importance of meaningfulness, where the low meaningfulness of type 4 will in the long run lead to low comprehension and manageability and, consequently, a lower SOC. The high meaningfulness of type 5 implies a good chance of an increase in comprehension and manageability, and consequently, a higher SOC. This is an example of another part of Antonovsky's salutogenic model that cannot be tested unless a scale is constructed that independently measures the three SOC components.

In sum, one task for future research is the development of a scale where the three SOC dimensions are measured relatively independently of each other. The procedure which can be used to construct a SOC scale with three uncorrelated or only modestly correlated dimensions is well known and straightforward (cf. e.g. DeVellis, 1991). In brief, the first step is to generate items, where each given item refers only to one of the three SOC dimensions (and where the four remaining facets are not taken into consideration when generating these items). The second step, using factor analysis, is to sort out and retain those items that clearly and consistently produce the three SOC dimensions.

\section{SOC as the Causal Variable}

The central postulate in Antonovsky's model is that SOC protects against ill health and, more importantly, promotes health (Antonovsky, 1979, 1987). To prove that SOC has a causal effect on health, at least the following four conditions must be met: (1) the measurement of SOC should precede the measurement of health in time, (2) there should be a statistically significant relation between SOC and health, (3) the relation between SOC and health should not be due to a third variable and (4) there should be a reasonable theoretical explanation of the relation between SOC and health (e.g. Taris and Kompier, 2003). Due to the reciprocity between SOC and health (Antonovsky, 1979, 1987; see also Fig. 53.1, e.g. arrows $\mathrm{R}, \mathrm{O}$ and $\mathrm{P}$ ) and as $\mathrm{SOC}$ also can be perceived as one of the indicators of (mental) health (e.g. Geyer, 1997), the causal effect of SOC on health is extra tricky to investigate. Given Antonovsky's assumption that SOC is a quite stable disposition after 30 years of age (Antonovsky, 1979, 1987), then cross-sectional data analysed with simple statistical methods can only at best give preliminary results on the causal relation between the trait-like SOC and state-like measures of health. A less strict view would be to describe and treat SOC as a determinant, moderator and mediator variable of health (e.g. Albertsen et al., 2001; Hochwälder, 2013). Also, the different possible types of relationships (e.g. simple, causal, reciprocal) between SOC and various health indicators should be more precisely specified and studied empirically. To rigorously study the causal effect of SOC on health, longitudinal data must be collected and properly ana- lysed, preferably by structural equation modelling analysis (e.g. Bollen, 1989; Byrne, 2001; DeLange et al., 2003; Taris and Kompier, 2003). Furthermore, it should also be noted that experimental studies to investigate the causal effect of SOC on other variables (e.g. stress, performance) are scarce (e.g. Kimhi, 2015; McSherry and Holm, 1994) and badly needed.

\section{SOC as the Outcome Variable}

Antonovsky $(1979,1987)$ assumed that SOC becomes a stable disposition around 30 years of age, especially for those with a strong initial SOC, and that it is difficult to change the SOC permanently in adults. However, empirical studies have shown that SOC is not as stable as Antonovsky assumed and that SOC increases slightly with age (see Eriksson and Lindström, 2005). Also, SOC can be improved through various interventions (e.g. Griffiths, 2009a, 2009b; Hojdahl et al., 2013; Kähönen et al., 2012; Langeland, 2007; Langeland et al., 2007a, 2013). According to the salutogenic model, a straightforward way to affect SOC is by (1) strengthening people's GRR; (2) by enhancing the environment with regard to (a) comprehensibility, by increasing predictability or consistency, (b) manageability, by creating an underload-overload balance and (c) meaningfulness, by increasing the participation in shaping of outcomes and (3) by improving people's tension management (see Antonovsky, 1979, 1987, 1996b; see also Fig. 53.1, arrows C, A and N). Langeland and coworkers (e.g. Langeland, 2007; Langeland et al., 2006, 2007b; Langeland and Vinje, 2013, 2017; Langeland and Wahl, 2009) have performed some promising interventions to strengthen SOC by targeting crucial GRR (e.g. social support, self-identity) and in various ways to enhance comprehensibility, manageability and meaningfulness. There is also evidence that improving tension management (e.g. through a mindfulness-based stress reduction programme, see Kabat-Zinn, 1982; Kabat-Zinn et al., 1985) can strengthen SOC (e.g. Weissbecker et al., 2002). Finally, there are also empirical findings indicating that various factors, such as personality (e.g. neuroticism, conscientiousness: see, e.g. Hochwälder, 2012; Feldt et al., 2007; Pallant and Lae, 2002), environment (e.g. life events, work conditions: see, e.g. Feldt et al., 2005; Kivimäki et al., 2002; Volanen et al., 2007), various types of social relationships and support (e.g. parent-child relationship, peer-group relationship: see, e.g. Garcia-Moya et al., 2014; Volanen, 2011; Volanen et al., 2004, 2006) as well as various types of behavioural and perceptual mechanisms (e.g. empowerment, reflection processes: see Super et al., 2016) are related to and can affect the SOC. Thus, even though it contradicts Antonovsky's original assumptions that SOC is a generalized disposition which is not susceptible to change in adult age, there are, as mentioned earlier, studies that have 
shown that various interventions can have positive effects on SOC, even though the permanence of these effects has not been established (see also, e.g. Eriksson, 2015b; Eriksson and Lindström, 2007; Lindström and Eriksson, 2005). Due to the positive relationship of the SOC to (mental) health - for a review, see Eriksson and Lindström (2006) - and to quality of life - for a review, see Eriksson and Lindström (2007) - more research is needed regarding how or in what way, to what degree and how permanently SOC can be strengthened in various groups and settings (e.g. Eriksson, 2015b; Suominen and Lindström, 2008).

\section{General SOC and Domain-Specific SOC}

The SOC scale is a general and trait-like measure because it was constructed to measure the generalized and dispositional way in which we perceive the world and life (Antonovsky, 1987). SOC - as measured by this scale - is often used to predict or explain various variables in specific domains (e.g. work; Albertsen et al., 2001) or to study how SOC is affected by an intervention on some variables in specific domains (e.g. work; Kähönen et al., 2012). In these cases, both the predictive power and the sensitivity to change would be enhanced if a domain-specific state measure of SOC were to be used (cf. Bandura, 1997; Quittner et al., 2012). Thus, when studying the predictive power or sensitivity to change in specific domains, it might be advisable in future research to use some of the existing domain-specific measures of SOC (e.g. work: Vogt et al., 2013; family: Antonovsky and Sourani, 1988; Rivera et al., 2012) and also, if needed, to develop new measures for some other domains (e.g. school, leisure time, spouse relation, parent-child relation).

\section{The Concept of Boundary in the Measurement of SOC}

Antonovsky (1979) stated in the salutogenic model that SOC can mobilize GRRs (e.g. coping strategies) to deal with various challenging life events (see Fig. 53.1, arrow D). Furthermore, Antonovsky (1987) also stated that the boundaries we set regarding parts of the world and life we consider to be important, influence our SOC. By restricting the boundaries, so that a particular sector (e.g. academic education) is considered as unimportant, that sector will no longer affect our SOC. By widening the boundaries, so that a certain sector is considered as important, that sector will affect our SOC. Furthermore, he suggested that the boundaries can never be restricted so much that the following four sectors are excluded: (1) the person's own inner feelings, (2) the closest interpersonal relations, (3) the main occupation and (4) the main existential themes. The SOC scale was constructed to include elements from these four sectors.
However, Antonovsky (1987) proposed that in the future, it would be wise to include a measure of the boundaries, or in other words, a measure of which sectors of the world and life a person takes into consideration when assessing that person's SOC. Such a measure of boundaries of SOC has still not been developed and remains a task for future research.

\section{The Dichotomization and Trichotomization of SOC}

Antonovsky (1987) sometimes treated - both theoretically and empirically - SOC as a dichotomized or trichotomized variable. To dichotomize or trichotomize a continuous quantitative variable has well-known disadvantages (see Cohen, 1983). However, if there is an imperfect or not very strong linear correlation between SOC and another variable, such as mental ill health, the question arises as to whether it is a strong SOC that protects against mental ill health or a weak SOC that is a risk factor. Antonovsky (1996b, p. 16) formulated this problem in the following way: 'Is there a linear relationship between SOC and health, or is having a particularly weak (or a particularly strong) SOC what matters?' Lundberg (1996) also asked if it could be the case that a strong SOC is not necessarily better for health than a moderate one and that a weak SOC that is especially detrimental for health.

Results from two studies are relevant to these questions. In a longitudinal study by Hochwälder (2015), the results indicated that persons with a weak SOC at Time 1 experienced (approximately 1 year later) at Time 2 more negative (conflict separation, integrity offensive and financial) life events than persons that had a moderate SOC or a strong SOC at Time 1. However, no differences between persons with moderate and strong SOC were found. A similar pattern was found in a study by Super et al. (2014), where the results showed that persons with weak SOC had a higher all-cause mortality risk compared to persons with moderate SOC, but that there was no difference between persons with moderate SOC and strong SOC. Thus, the findings from these two studies give some preliminary support to Lundberg's hypothesis (1996).

This gives rise to the following question - if it can be accepted that SOC should be dichotomized or trichotomized in order to be able to answer specific questions - how is this dichotomization or trichotomization to be carried out? One often-used strategy is to obtain relative, or sample specific cut-off values (e.g. Magnusson, 1967), which means that for a given sample or study the SOC scale is dichotomized by setting the cut-off value at the 50th percentile or trichotomized by setting the cut-off values at the 33rd (or 25th) and the 67th (or 75th) percentile on the SOC scale (e.g. Anson et al., 1993; Karlsson et al., 2000; Ristakari et al., 2008; Surtees et al., 2006a). The shortcoming with this approach is that the cut-off points vary between studies and that the dif- 
ferentiation between the SOC groups in a given study depends on the distribution on the SOC scale in that study. This means that if, for example, most subjects in the distribution have similar values on the SOC scale, then there will be no apparent differences between the different SOC groups. Another strategy is to set absolute or non-sample specific cut-off values (e.g. Magnusson, 1967), which means that the dichotomization or trichotomization is based on previously established cut-off values for the SOC scale (e.g. Langius and Björnvell, 1996). Concerning this approach, it should be noted that there are no well-established cut-off values for the SOC scale (Eriksson and Lindström, 2005, 2006), and also, that when this approach is used, the cut-off points are usually not established through rigorous psychometric analyses to ensure discriminant validity between the different groups (e.g. Magnusson, 1967; Murphy and Davidshofer, 2001). Thus, one task for future research on the SOC scale is to use psychometric analyses to establish absolute cut-off values for the SOC scale that clearly and distinctively separate the different SOC groups from each other.

In sum, even though there are disadvantages in dichotomizing or trichotomizing SOC, it is suggested that it can be justified in order to be able to investigate more thoroughly if a weak SOC or a strong SOC is crucial for health and wellbeing. Furthermore, it should also be investigated whether it is a weak SOC or a strong SOC that is crucial, depending on the variable being studied, for example, whether the variable is pathogenic (e.g. hassles or depression) or salutogenic (e.g. uplifts or happiness). Finally, an additional issue is to establish absolute cut-off values for the SOC scale, which could be used generally and universally. These three types of issues deserve more attention in future research.

\section{The Importance of Relating SOC to Salutogenic Outcomes Measures}

Antonovsky $(1979,1987)$ stated that the salutogenic perspective should be a complement to the older and more established pathogenic perspective. Even though it is noteworthy that the latter had a dominating position over the salutogenic perspective for a long period, this is quite understandable from a psychological and evolutionary point of view. The research on prospect theory by Kahneman and Tversky (1979; see also Kahneman, 2011) has showed, among other things, the principle of loss aversion, which states that when the same objective losses and gains are compared with each other, the losses are usually subjectively perceived as $1.5-2.5$ times larger than the gains. This means that we are driven more strongly to avoid losses than to achieve gains or that bad is stronger than good (see also, e.g. Baumeister et al., 2001). In the present context, this could be interpreted to mean that we humans are more motivated to avoid becoming worse or 'unhealthy' than better or 'healthy,' as we value this more highly.
Table 53.3 Mapping sentence definition of the health ease/dis-ease continuum (Antonovsky, 1979, p. 65)

\begin{tabular}{|c|c|c|}
\hline & A. Pain & \\
\hline \multirow{2}{*}{$\begin{array}{l}\text { Breakdown is any } \\
\text { state or condition of } \\
\text { the human organism } \\
\text { that is felt by the } \\
\text { individual to be: }\end{array}$} & $\begin{array}{l}\text { 1. Not at all } \\
\text { 2. Mildly } \\
\text { 3. Moderately } \\
\text { 4. Severely }\end{array}$ & Painful \\
\hline & $\begin{array}{l}\text { B. Functional } \\
\text { limitation }\end{array}$ & \\
\hline \multirow[t]{2}{*}{$\begin{array}{l}\text { That is felt by him or } \\
\text { her to be: }\end{array}$} & $\begin{array}{l}\text { 1. Not at all } \\
\text { 2. Mildly } \\
\text { 3. Moderately } \\
\text { 4. Severely }\end{array}$ & $\begin{array}{l}\text { Limiting for the } \\
\text { performance of life } \\
\text { activities self- } \\
\text { defined as } \\
\text { appropriate }\end{array}$ \\
\hline & $\begin{array}{l}\text { C. Prognostic } \\
\text { implication }\end{array}$ & \\
\hline \multirow[t]{2}{*}{$\begin{array}{l}\text { That would be defined } \\
\text { by the professional } \\
\text { health authorities as: }\end{array}$} & $\begin{array}{l}\text { 1. Not acute or } \\
\text { chronic } \\
\text { 2. Mild, acute and } \\
\text { self-limiting } \\
\text { 3. Mild, chronic } \\
\text { and stable } \\
\text { 4. Serious, chronic } \\
\text { and stable } \\
\text { 5. Serious, chronic } \\
\text { and degenerative } \\
\text { 6. Serious, acute } \\
\text { and } \\
\text { life-threatening }\end{array}$ & Condition \\
\hline & $\begin{array}{l}\text { D. Action } \\
\quad \text { implication }\end{array}$ & \\
\hline $\begin{array}{l}\text { And that would be } \\
\text { seen by such } \\
\text { authorities as } \\
\text { requiring: }\end{array}$ & $\begin{array}{l}\text { 1. No particular } \\
\text { health-related } \\
\text { action } \\
\text { 2. Efforts at } \\
\text { reduction of } \\
\text { known risk } \\
\text { factors } \\
\text { 3. Observation, } \\
\text { supervision or } \\
\text { investigation by } \\
\text { the healthcare } \\
\text { system } \\
\text { 4. Active } \\
\text { therapeutic } \\
\text { intervention }\end{array}$ & \\
\hline
\end{tabular}

According to Antonovsky (1979, 1987), a person's health is not a dichotomy but should be conceptualized as a position on an ease/dis-ease continuum. More specifically, he presented a definition of the health ease/dis-ease continuum, which is mapped in Table 53.3 (Antonovsky, 1979, p. 65). As can be seen from the table, a person's health could be assessed by ratings on four facets or domains (pain, functional limitation, prognostic implication and action implication), where the rating in each domain is placed into a number of categories (4, 4, 6 and 4 categories respectively), which results in $384(=4 \times 4 \times 6 \times 4)$ possible health profiles. It should be noted that this definition is pathogenic, because: (a) it focuses on the absence of ill health in terms of pain, 
functional limitations, prognostic implications and action implications, where at best the person has 'not at all' pain, has 'not at all' functional limitation, has 'not acute or chronic' prognostic implications and has 'no particular health-related action' with regard to action implications; (b) of the 384 possible profiles only one (the 1-1-1-1 profile) is characterized by the total absence of problems. Thus, it seems that Antonovsky also focuses asymmetrically more on ill health or the dis-ease part in his definition of health.

In Antonovsky's defence (see Antonovsky, 1979, 1987), it must be said that to him, the movement on this continuum was the primary concern and not the position per se. Furthermore, his salutogenic perspective focuses primarily on what makes people move towards health and not about how to avoid ill health. As presented previously (see Table 53.1), while the salutogenic perspective focuses on promoting better health, gains, growth and maximizing potentials, the pathogenic perspective focuses on treating or preventing diseases, pain or loss, becoming worse and minimizing problems. It is then logical that the pathogenic approach uses pathogenic outcome measures such as burnout, anxiety, depression, the prevalence of various diseases (e.g. cancer, coronary heart diseases) and mortality. It would be equally logical that the salutogenic approach would more frequently use salutogenic measures of positive health and well-being as outcome variables.

The problem is, however, that in the majority of the salutogenic studies or studies having had the intention to follow in Antonovsky's footsteps, pathogenic variables are measured as outcome variables, with the consequence that the core idea of the salutogenic perspective is not adequately investigated (see Becker et al., 2010). In order to adequately study the fundamental thought that SOC promotes movement towards the positive side of the ease/dis-ease continuum or in other words, the existing salutogenic variables - such as, for example, perceived wellness (Adams et al., 1997), wellness promotion (Becker et al., 2008, 2009), mental health (Keyes, 2005) and healthy lifestyle (Berger and Walker, 1997; Walker et al., 1987) - should be used more frequently as outcome measures and, if necessary, new scales should be developed to measure various types of salutogenic outcome variables.

\section{Additional Issues of Various Kinds}

There are additional issues of various kinds that are highly relevant to Antonovsky's salutogenic model and which should be given more attention in future research. Three such issues will be mentioned briefly here. First, SOC is usually measured for individuals (individual SOC), but could also be measured for other entities, such as groups (e.g. families) and places (e.g. workplaces) (collective SOC). The study of collective SOC is an avenue with many theoretical chal- lenges (e.g. concerning its development and stability) and empirically, relatively sparsely investigated (e.g. the study of, and comparison between, different workplaces, where the multilevel analysis seems particularly well suited to analyse the data, see, e.g. Bickel, 2007; Twisk, 2006), which deserves more attention in future research (see, e.g. Antonovsky, 1996b; Bauer et al., 2019). Second, when Antonovsky introduced the scale for measuring the SOC construct, it generated much research related to the salutogenic model (see, e.g. Antonovsky, 1987, 1993). It should be noted that there are no established scales to measure many of the other central constructs (e.g. GRRs, tension management) in the salutogenic model (see Fig. 53.1), and if scales could be developed to measure these constructs, it would probably stimulate much research related to this model. Third, as the number of studies relating to parts of the model grows, it becomes important to summarize these findings in the form of literature reviews and meta-studies. Many valuable reviews have already been done (e.g. Eriksson and Lindström, 2005, 2006, 2007; Flensborg-Madsen et al., 2005; Mittelmark et al., 2017), and hopefully more such studies will be done in the future to summarize findings on issues relating to Antonovsky's salutogenic model of health.

\section{Conclusions}

Antonovsky's salutogenic model of health, with its core construct of SOC, has become an important complement to the pathogenic model. Throughout the years, the salutogenic model has provided valuable guidance and stimulated much research. However, several theoretical and methodological issues need to be addressed. The aim of this chapter has been to discuss some issues that need to be further explored in future research. More specifically, the following issues were discussed: (1) the dimensionality of the SOC scale; (2) SOC as the causal variable; (3) SOC as the outcome variable; (4) general SOC versus domain-specific SOC; (5) the concept of boundary in the measurement of SOC; (6) the dichotomization and trichotomization of SOC; (7) the importance of relating SOC to salutogenic outcome measures; (8) various kinds of additional issues: (a) studying the collective SOC, (b) measuring other central constructs in the salutogenic model and (c) the importance of literature reviews and meta-studies.

\section{References}

Adams, T., Bezner, J., \& Steinhardt, M. (1997). The conceptualization and measurement of perceived wellness: Integrating balance across and within dimensions. American Journal of Health Promotion, 11, 208-218

Albertsen, K., Nielsen, M. L., \& Borg, V. (2001). The Danish psychosocial work environment and symptoms of stress: The main, mediat- 
ing and moderating role of sense of coherence. Work \& Stress, 15, 241-253.

Anson, O., Carmel, S., Levenson, A., Bonneh, D. Y., \& Maoz, B. (1993). Coping with recent life events: The interplay of personal and collective resources. Behavioral Medicine, 18, 159-166.

Antonovsky, A. (1979). Health, stress and coping. Jossey-Bass.

Antonovsky, A. (1987). Unravelling the mystery of health: How people manage stress and stay well. Jossey-Bass.

Antonovsky, A. (1993). The structure and properties of the sense of coherence scale. Social Sciences \& Medicine, 36, 725-733.

Antonovsky, A. (1996a). Aaron Antonovsky's last article. The sense of coherence: An historical and future perspective. Israeli Journal of Medical Sciences, 32, 170-178.

Antonovsky, A. (1996b). The salutogenic model as a theory to guide health promotion. Health Promotion International, 11, 11-18.

Antonovsky, A., \& Sourani, T. (1988). Family sense of coherence and family adaption. Journal of Marriage and Family, 50, 79-92.

Bandura, A. (1997). Self-efficacy: The exercise of control. Freeman.

Bauer, G. F., Roy, M., Bakibinga, P., Contu, P., Downe, S., Eriksson, M., \& Vinje, H. F. (2019). Future directions for the concept of salutogenesis: A position article. Health Promotion International, 34(2), 1-9.

Baumeister, R. F., Bratslavsky, E., Finkenauer, C., \& Vohs, K. D. (2001). Bad is stronger than good. Review of General Psychology, 5, 323-370.

Becker, C. M., Glascoff, M. A., \& Felts, W. M. (2010). Salutogenesis 30 years later: Where do we go from here? International Electronic Journal of Health Education, 13, 25-32.

Becker, C. M., Moore, J. B., Whetstone, L., Glascoff, M., Chaney, E., Felts, M., \& Anderson, L. (2009). Validity evidence for the salutogenic wellness promotion scale (SWPS). American Journal of Health Behavior, 33, 455-465.

Becker, C. M., Whetstone, L., Glascoff, M., \& Moore, J. (2008). Evaluation of the reliability and validity of an adult version of the salutogenic wellness promotion scale (SWPS). American Journal of Health Education, 39, 322-328.

Berger, A. M., \& Walker, S. N. (1997). Measuring healthy lifestyle. In M. Frank-Stromborg \& S. J. Olsen (Eds.), Instruments for clinical health-care research (pp. 373-377). Jones and Bartlett Publishers.

Bickel, R. (2007). Multilevel analysis for applied research. Guilford Publications.

Bollen, K. A. (1989). Structural equations with latent variables. Wiley.

Byrne, B. M. (2001). Structural equation modelling with AMOS: Basic concepts, applications, and programming. Lawrence Erlbaum Associates, Publishers.

Chalmers, A. F. (1982). What is this thing called science? (2nd ed.). Open University Press.

Cohen, J. (1983). The cost of dichotomization. Applied Psychological Measurement, 7, 249-253.

DeLange, A. H., Taris, T. W., Houtman, I. L. D., \& Bongers, P. M. (2003). "The very best of the millennium": Longitudinal research and the demand-control-(support) model. Journal of Occupational Health Psychology, 8, 282-305.

DeVellis, R. F. (1991). Scale development: Theory and applications. Sage Publications.

Eriksson, M. (Ed.) (2015a). Salutogenes: Om hälsans ursprung [Salutogenesis: The origins of health] Stockholm: Liber.

Eriksson, M. (2015b). Kritik av den salutogena teorin [Criticism of the salutogenic theory]. In M. Eriksson (Ed.), Salutogenes: Om hälsans ursprung (sid. 78-91). [Salutogenesis: On origins of health]. Stockholm: Liber

Eriksson, M., \& Lindström, B. (2005). Validity of Antonovsky's sense of coherence scale: A systematic review. Journal of Epidemiology and Community Health, 59, 460-466.
Eriksson, M., \& Lindström, B. (2006). Antonovsky's sense of coherence scale and the relation with health: A systematic review. Journal of Epidemiology and Community Health, 60, 376-381.

Eriksson, M., \& Lindström, B. (2007). Antonovsky's sense of coherence scale and the relation with quality of life: A systematic review. Journal of Epidemiology and Community Health, 61, 938-944.

Feldt, T., Leskinen, E., \& Kinnunen, U. (2005). Structural invariance and stability of sense of coherence: A longitudinal analysis of two groups with different employment experiences. Work \& Stress, 19, 68-83.

Feldt, T., Metsäpelto, R.-T., Kinnunen, U., \& Pulkkinen, L. (2007). Sense of coherence and five-factor approach to personality: Conceptual relationships. European Psychologist, 12, 165-172.

Flensborg-Madsen, T., Ventegodt, S., \& Merrick, J. (2005). Why is Antonovsky's sense of coherence not correlated to physical health? Analysing Antonovsky's 29-item sense of coherence scale (SOC29). The Scientific World Journal, 5, 767-776.

Garcia-Moya, I., Moreno, C., \& Rivera, F. (2014). Obtaining a hierarchy of contextual factors in shaping the SOC of male and female adolescents. Journal of Happiness Studies, 15, 1267-1287.

Geyer, S. (1997). Some conceptual considerations on the sense of coherence. Social Sciences and Medicine, 44, 1771-1779.

Griffiths, C. A. (2009a). Sense of coherence and mental health rehabilitation. Clinical Rehabilitation, 23, 72-78.

Griffiths, C. A. (2009b). The EMILIA project: The impact of a lifelong learning intervention on the sense of coherence of mental health service users. International Journal of Psychosocial Rehabilitation, $14,35-49$.

Griffiths, C. A. (2010). A critical analysis of Antonovsky's sense of coherence theory in relation to mental health and mental disorder and the effect of a lifelong learning intervention on sense of coherence of mental health service users (Doctoral dissertation). London: Middlesex University.

Guttman, L. (1974). Measurement as structural theory. Psychometrika, 36, 329-347.

Hochwälder, J. (2012). The contribution of the big five personality factors to sense of coherence. Personality and Individual Differences, $53,591-596$

Hochwälder, J. (2013). Negative life events and mental ill-health among women: A prospective study of the main, moderating and mediating effect of sense of coherence. Journal of Happiness Studies, 14, $1739-1750$.

Hochwälder, J. (2015). Test of Antonovsky's postulate: High sense of coherence helps people avoid negative life events. Psychological Reports, 116, 363-376.

Hojdahl, T., Magnus, J. H., Hagen, R., \& Langeland, E. (2013). "VINN"- An accredited motivational program promoting convicted women's sense of coherence and coping. EuroVista, 2, 177-190.

Kabat-Zinn, J. (1982). An outpatient program in behavioral medicine for chronic pain patients based on the practice of mindfulness meditation: Theoretical considerations and preliminary results. General Hospital Psychiatry, 4, 33-47.

Kabat-Zinn, J., Lipworth, L., \& Burney, R. (1985). The clinical use of mindfulness meditation for self-regulation of chronic pain. Journal of Behavioral Medicine, 8, 163-190.

Kahneman, D. (2011). Thinking, fast and slow. Penguin Books.

Kahneman, D., \& Tversky, A. (1979). Prospect theory: An analysis of decision under risk. Econometrica, 47, 263-291.

Kähönen, K., Näätänen, P., Tolvanen, A., \& Salmela-Aro, K. (2012). Development of sense of coherence during two group interventions. Scandinavian Journal of Psychology, 53, 523-527.

Karlsson, I., Berglin, E., \& Larsson, P. A. (2000). Sense of coherence: Quality of life before and after coronary artery bypass surgery - A longitudinal study. Journal of Advanced Nursing, 31, 1383-1392. 
Keyes, C. (2005). Mental health and/or mental illness? Investigating axioms of the complete state model of health. Journal of Consulting and Clinical Psychology, 73, 539-548.

Kimhi, S. (2015). Sense of coherence and gender as a predictor of the effect of laboratory induced stress on cognitive performance. The Journal of Psychology, 149, 412-426.

Kivimäki, M., Vahtera, J., Elovainio, M., Lillrank, B., \& Kevin, M. V. (2002). Death or illness of a family member, violence, interpersonal conflict, and financial difficulties as predictors of sickness absence: Longitudinal cohort study on psychological and behavioral links. Psychosomatic Medicine, 64, 817-825.

Kumlin, T. (Ed.) (1998a). Känsla av sammanhang i teori, empiri och kritik [Sense of coherence: Theory, empiricism, and criticism]. Stockholm: Forskningsrådsnämnden.

Kumlin, T. (Ed.) (1998b). Röster om KASAM. 15 forskare granskar begreppet känsla av sammanhang [Voices on SOC. 15 researchers review the concept of sense of coherence]. Stockholm: Forskningsrådsnämnden.

Langeland, E. (2007). Sense of coherence and life satisfaction in people suffering from mental health problems: An intervention study in talk-therapy groups with focus on salutogenesis (Doctoral dissertation). University of Bergen.

Langeland, E., Riise, T., Hanestad, B. R., Nortvedt, M. W., Kristoffersen, K., \& Wahl, A. K. (2006). The effect of salutogenic treatment principles on coping with mental health problems: A randomised controlled trial. Patient Education and Counselling, 62, 212-219.

Langeland, E., Robinson, H. S., Moun, T., Larsen, M. H., Krogstad, A.-L., \& Wahl, A. K. (2013). Promoting sense of coherence: Salutogenesis among people with psoriasis undergoing patient education in climate therapy. BMC Psychology, 1, 1-8.

Langeland, E., \& Vinje, H. F. (2013). The significance of salutogenesis and well-being in mental health promotion; from theory to practice. In C. Keyes (Ed.), Mental well-being: International contributions to the study of positive mental health (pp. 299-329). Springer.

Langeland, E., \& Vinje, H. F. (2017). The application of salutogenesis in mental health settings. In M. B. Mittelmark, S. Sagy, M. Eriksson, G. F. Bauer, J. M. Pelikan, B. Lindström, \& G. A. Espnes (Eds.), The handbook of salutogenesis (pp. 299-305). Springer International Publishing AG.

Langeland, E., \& Wahl, A. K. (2009). The impact of social support on mental health service users' sense of coherence: A longitudinal panel survey. International Journal of Nursing Studies, 46, 830-837.

Langeland, E., Wahl, A. K., Kristoffersen, K., Nortvedt, M. W., \& Hanestad, B. R. (2007a). Sense of coherence predicts change in life satisfaction among home-living residents in the community with mental health problems: A 1-year follow-up study. Quality of Life Research, 16, 939-946.

Langeland, E., Wahl, A. K., Kristoffersen, K., Nortvedt, M. W., \& Hanestad, B. R. (2007b). Promoting coping: Salutogenesis among people with mental health problems. Issues in Mental Health Nursing, 28, 275-295.

Langius, A., \& Björvell, H. (1996). The salutogenic model and the use of the sense of coherence scale in nursing research - A methodological report. Nordic Journal of Nursing Research, 16, 28-31.

Lewin, K. (1951). Problems of research in social psychology. In D. Cartwright (Ed.), Field theory in social science: Selected theoretical papers (pp. 155-169). Harper \& Row.

Lindström, B., \& Eriksson, M. (2005). Salutogenesis. Journal of Epidemiology and Community Health, 59, 440-442.

Lundberg, O. (1996). "Sense of coherence" och befolkningens hälsa. Sosiaalilääketieteellinen Aikakauslehti, 33, 265-273.

Magnusson, D. (1967). Test theory. Addison-Wesley.

McSherry, W. C., \& Holm, J. E. (1994). Sense of coherence: It's effects on psychological and physiological processes prior to, during, and after a stressful situation. Journal of Clinical Psychology, 50, 476-487.
Mittelmark, M. B., Sagy, S., Eriksson, M., Bauer, G. F., Pelikan, J. M., Lindström, B., \& Espnes, G. A. (Eds.). (2017). The handbook of salutogenesis. Springer International Publishing AG.

Murphy, K. R., \& Davidshofer, C. O. (2001). Psychological testing: Principles and applications (5th ed.). Prentice Hall.

Pallant, J. F., \& Lae, L. (2002). Sense of coherence, well-being, coping and personality factors: Further evaluation of the sense of coherence scale. Personality and Individual Differences, 33, 39-48.

Quittner, A. L., Sawicki, G. S., McMullen, A., Rasouliyan, L., Pasta, D. J., Yegin, A., \& Konstan, M. W. (2012). Psychometric evaluation of the cystic fibrosis questionnaire-revised in a national sample. Quality of Life Research, 21, 1267-1278.

Ristakari, T., Sourander, A., Ronning, J. A., Nikolakaros, G., \& Helenius, H. (2008). Life events, self-reported psychopathology and sense of coherence among young men: A population-based study. Nordic Journal of Psychiatry, 62, 464-471.

Rivera, F., Garcia-Moya, I., Moreno, C., \& Ramos, P. (2012). Developmental contexts and sense of coherence in adolescence: A systematic review. Journal of Health Psychology, 18, 800-812.

Shye, S. (1978). Theory construction and data analysis in the behavioral sciences. Jossey-Bass.

Suominen, S., \& Lindström, B. (2008). Salutogenesis. Scandinavian Journal of Public Health, 36, 337-339.

Super, S., Verschuren, W. M. M., Zantinge, E. M., Wagemakers, M. A. E., \& Picavet, H. S. J. (2014). A weak sense of coherence is associated with a higher mortality risk. Journal of Epidemiology and Community Health, 68, 411-417.

Super, S., Wagemakers, M. A. E., Picavet, H. S. J., Verkooijen, K. T., \& Koelen, M. A. (2016). Strengthening sense of coherence: Opportunities for theory building in health promotion. Health Promotion International, 31, 869-878.

Surtees, P. G., Wainwright, N. W., Luben, R., Khaw, K. T., \& Day, N. E. (2003). Sense of coherence and mortality in men and women in the EPIC-Norfolk United Kingdom prospective cohort study. American Journal of Epidemiology, 158, 1202-1209.

Surtees, P. G., Wainwright, N. W. J., \& Khaw, K. T. (2006a). Resilience, misfortune, and mortality: Evidence that sense of coherence is a marker of social stress adaptive capacity. Journal of Psychosomatic Research, 61, 221-227.

Surtees, P. G., Wainwright, N. W., Luben, R., Khaw, K. T., \& Day, N. E. (2006b). Mastery, sense of coherence, mortality: Evidence of independent associations from the EPIC-Norfolk prospective cohort study. Health Psychology, 25, 102-110.

Taris, T. W., \& Kompier, M. (2003). Challenges in longitudinal designs in occupational health psychology. Scandinavian Journal of Work Environmental Health, 29, 1-4.

Twisk, J. W. R. (2006). Applied multilevel analysis. Cambridge University Press.

Vinje, H. F., Langeland, E., \& Bull, T. (2017). Aaron Antonovsky's development of salutogenesis, 1979 to 1994. In M. B. Mittelmark, S. Sagy, M. Eriksson, G. F. Bauer, J. M. Pelikan, B. Lindström, \& G. A. Espnes (Eds.), The handbook of salutogenesis (pp. 25-40). Springer International Publishing AG.

Vogt, K., Jenny, G. J., \& Bauer, G. F. (2013). Comprehensibility, manageability and meaningfulness at work: Construct validity of a scale measuring work-related sense of coherence. South African Journal of Industrial Psychology, 39, 1-8.

Volanen, S-M. (2011). Sense of coherence: Determinants and Consequences (Doctoral dissertation). University of Helsinki.

Volanen, S.-M., Lahelma, E., Silventoinen, K., \& Suominen, S. (2004). Factors contributing to sense of coherence among men and women. European Journal of Public Health, 14, 322-330.

Volanen, S.-M., Suominen, S., Lahelma, E., Koskenvuo, M., \& Silventoinen, K. (2006). Sense of coherence and its determinants: A comparative study of the Finnish-speaking majority and the 
Swedish-speaking minority in Finland. Scandinavian Journal of Public Health, 34, 515-525.

Volanen, S.-M., Suominen, S., Lahelma, E., Koskenvuo, M., \& Silventoinen, K. (2007). Negative life events and stability of sense of coherence: A five-year follow-up study of Finnish women and men. Scandinavian Journal of Psychology, 48, 433-441.

Walker, S. N., Sechrist, K. R., \& Pender, N. J. (1987). The healthpromoting lifestyle profile: Development and psychometric characteristics. Nursing Research, 36, 76-81.
Weissbecker, I., Salmon, P., Studts, J. L., Floyd, A. R., Dedert, E. A., \& Sephton, S. E. (2002). Mindfulness-based stress reduction and sense of coherence among women with fibromyalgia. Journal of Clinical Psychology in Medical Settings, 9, 297-307.

Open Access This chapter is licensed under the terms of the Creative Commons Attribution 4.0 International License (http://creativecommons. org/licenses/by/4.0/), which permits use, sharing, adaptation, distribution and reproduction in any medium or format, as long as you give appropriate credit to the original author(s) and the source, provide a link to the Creative Commons license and indicate if changes were made.

The images or other third party material in this chapter are included in the chapter's Creative Commons license, unless indicated otherwise in a credit line to the material. If material is not included in the chapter's Creative Commons license and your intended use is not permitted by statutory regulation or exceeds the permitted use, you will need to obtain permission directly from the copyright holder. 